\title{
Análise de patentes de tecnologias relacionadas ao descarte de resíduos de equipamentos elétricos e eletrônicos com vistas à sustentabilidade ambiental ${ }^{12}$
}

\begin{abstract}
Analysis of technology patents related to the disposal of electric and electronic equipment waste regarding the environmental sustainability
\end{abstract}

\author{
Luciara Cid Gigante ${ }^{3}$ \\ Maria Cristina Comunian Ferraz \\ Camila Carneiro Dias Rigolin
}

\section{Resumo}

Esta pesquisa, de caráter interdisciplinar, aliou aspectos teóricos do campo Ciência, Tecnologia e Sociedade (CTS) e Sociologia do Consumo através de uma das metodologias da Ciência da Informação. Teve como objetivo realizar a análise de patentes de tecnologias relacionadas ao descarte de lixo tecnológico e das tendências verificadas em documentos de patentes, por meio de monitoramento tecnológico de produtos e processos na base de dados de patentes gratuita online Espacenet. Como resultados, foram evidenciados grandes contrastes em reivindicações puramente técnicas de

3 Luciara Cid Gigante: Mestre em Ciência, Tecnologia e Sociedade pela Universidade Federal de São Carlos (UFSCar) e doutoranda em Política Científica e Tecnológica pela Universidade Estadual de Campinas (UNICAMP). E-mail: luciaragigante@ige.unicamp.br.

Maria Cristina Comunian Ferraz: Doutorado em Ciências pelo Instituto de Física e Química de São Carlos, com Pós-doutorado em Engenharia de Materiais e Especialização em Administração e Análise de Negócios. Professora Associada da Universidade Federal de São Carlos (UFSCar) vinculada ao Departamento de Ciência da Informação é tutora de alunos indígenas (Grupo PET), coordenadora de programa de extensão (Divulgação Científica, Comunicação e Inclusão Social), docente de programa de mestrado (Ciência, Tecnologia e Sociedade) e de curso de especialização (Gestão de Organizações Públicas) na UFSCar. E-mail: cristina@ufscar.br.

Camila Carneiro Dias Rigolin: Doutorada em Política Científica e Tecnológica pela Universidade Estadual de Campinas (UNICAMP), com estágio de doutoradosanduíche no Departamento de Antropologia, Indiana University, EUA (2007-2008). Mestre em Administração (UFBA). Professora Adjunto da Universidade Federal de São Carlos (UFSCar) vinculada ao Departamento de Ciência da Informação e do Programa de Pós-Graduação em Ciência, Tecnologia e Sociedade (PPGCTS), do qual é vice-coordenadora. Coordenadora do Núcleo de Estudos sobre Expertise e Política e pesquisadora associada do Laboratório de Estudos Sociais em Ciência, Tecnologia e Sociedade, grupos de pesquisa da Universidade Federal de São Carlos, cadastrados no DGP-CNPq. Áreas de atuação em pesquisa: Estudos Sociais de Ciência e Tecnologia e Política Científica e Tecnológica. E-mail: diasrigolin@ufscar.br 
documentos de patentes que levaram em consideração mais do que somente a descrição sumária da tecnologia em questão, mas também com aspectos relativos à sustentabilidade sócio-econômica-ambiental. Concluiuse que universidades, governo e sociedade têm que se unir para que novas práticas ambientalmente seguras sejam criadas e adotadas mundialmente a fim de que parte do impacto já gerado seja revertido, ou, que novos impactos não sejam gerados, ou apenas minimizados.

Palavras-chave: Ciência, Tecnologia e Sociedade; Propriedade Intelectual; Análise de patentes; Equipamentos elétricos e eletrônicos; Política Nacional de Resíduos Sólidos.

\section{Abstract}

This interdisciplinary research gathered theoretical aspects in the field of Science, Technology and Society (STS) as well as Sociology of Consumption through one of the methodologies of the Information Science. The objective was to analyze the technology patents related to the disposal of technological waste and the trends verified in documents of patents, through the technological monitoring of products and processes on online free patent database: Espacenet. In the results great contrasts were highlighted. These in pure technical claims of patent documents which took into consideration more than only the brief description of the technology in question, but also aspects related to the social, economical and environmental sustainability. It was concluded that universities, the government and the society must unite in order to promote new and safer environmental practices that could be created and adopted worldwide so that part of the generated impact could be minimized or new impacts are not even generated, or merely minimized.

Keywords: Science, Technology and Society; Intellectual Property; Patent Analysis; Electric and Electronic Equipment; National Policy of Solid Waste.

\section{Introdução}

De modo geral, segundo López Cerezo (1998), os estudos sobre "Ciência, Tecnologia e Sociedade" (CTS) constituem um campo de trabalho que trata de entender o fenômeno científico-tecnológico no contexto social, tanto em relação aos condicionantes sociais como em relação às suas consequências socioambientais.

Por se tratar de um campo de trabalho acadêmico de caráter crítico e interdisciplinar, segundo Bazzo, Linsingen e Pereira (2003), existem diversas orientações acadêmicas, como as provenientes da sociologia do conhecimento científico ou da história da tecnologia. De âmbitos de reflexão e de propostas de mudança institucional, como a ética engenheril ou os estudos de avaliação de tecnologias, convergem neste heterogêneo campo de trabalho. 
Enfatizando a dimensão social da ciência e da tecnologia, atualmente os estudos CTS constituem uma diversidade de programas de colaboração multidisciplinar que força a concorrência entre suas duas tradições (europeia e norte-americana), as quais, segundo López Cerezo (2002, p. 9), compartilham: "a) a rejeição da imagem da ciência como uma atividade pura; b) a crítica da concepção da tecnologia como ciência aplicada e neutra; e, c) a condenação da tecnocracia".

Neste sentido, esta pesquisa partiu da expressão "capitalismo flexível" que descreve hoje um sistema que é mais que uma variação sobre um velho tema. Enfatiza-se a flexibilidade. Atacam-se as formas rígidas de burocracia, e também os males da rotina cega (SENNETT, 2010).

Harvey (1993, p. 148) explana que os sistemas de produção flexível permitiram a aceleração do ritmo da inovação do produto, ao lado da exploração de nichos de mercado altamente especializados e de pequena escala. "Em condições recessivas e de aumento da competição, o impulso de explorar essas possibilidades tornou-se fundamental para a sobrevivência".

Para o autor, o tempo de giro, que sempre é uma chave da lucratividade capitalista, foi reduzido de modo dramático pelo uso de novas tecnologias produtivas (automação, robôs) e de novas formas organizacionais (como o sistema de gerenciamento de estoques "just-intime", que corta drasticamente a quantidade de material necessária para manter a produção fluindo).

Harvey (1993, p. 148) ressalta que "a aceleração do tempo de giro na produção teria sido inútil sem a redução do tempo de giro no consumo". A meia vida de um produto fordista típico, por exemplo, era de cinco a sete anos, mas a acumulação flexível diminuiu isso em mais da metade em setores como o têxtil, enquanto que em outros, como o de tecnologias de informação (videogames e programas de computador), a meia vida tem caído para menos de dezoito meses. A acumulação foi acompanhada na ponta do consumo pela mobilização de todos os artifícios de indução de necessidades e de transformação cultural. A estética, relativamente estável do modernismo fordista cedeu lugar à instabilidade e qualidades fugidias de uma estética pós-moderna que celebra a diferença, a efemeridade, o espetáculo e a mercadificação das formas culturais (HARVEY, 1993).

Neste contexto, o problema do grande volume de resíduos sólidos gerados por bilhões de consumidores tem sido apontado como um dos mais graves da atualidade. A escassez cada vez maior de áreas para a implantação de novos aterros para a disposição de resíduos, aliada às limitações existentes para a recuperação dos materiais não renováveis, o baixo grau de implantação de novas alternativas de tratamento e reciclagem, representam hoje, um grande desafio.

Como afirmam Ferraz e Basso (2003) "a geração de resíduos é um dos maiores problemas enfrentados, hoje em dia, pelo sistema produtivo." Por isso, dada a grande escala de produção, tornou-se evidente, nas últimas décadas, a limitação dos ecossistemas naturais em decomporem os resíduos gerados pelo homem em sua atividade econômica (FERRAZ; BASSO, 2003). 
Esta pesquisa teve como objetivo principal fazer a análise de patentes de tecnologias relacionadas ao descarte de lixo tecnológico e as tendências verificadas por meio de documentos de patentes, através de monitoramento tecnológico de produtos e processos relacionados ao descarte de lixo tecnológico na base de dados de patentes gratuita online Espacenet.

Como objetivos específicos constaram: identificar e categorizar os tipos de materiais classificados como lixo tecnológico; detectar para quais tipos de materiais com essa classificação já existem políticas de descarte; levantar e avaliar as tendências tecnológicas encontradas nos documentos de patentes, através de análise de conteúdo; comparar tais tendências levantadas nos documentos de patentes com a situação atual vigente na legislação brasileira de descarte de lixo tecnológico.

Este estudo justificou-se tendo em vista que analisar as tecnologias existentes para que o descarte de lixo tecnológico seja feito de maneira a colaborar para o crescimento socioeconômico de maneira sustentável, propiciará benefícios a toda a sociedade com ganhos econômicos, sociais e ambientais.

A pertinência desta pesquisa se destacou também pelo ineditismo do tema que alia o estudo das políticas públicas existentes sobre descarte de lixo tecnológico às inovações patenteadas sobre o tema. Esperava-se estabelecer um diálogo entre a área da Propriedade Intelectual e os estudos do campo CTS, ao relacioná-las com o uso de patentes como fonte de informação tecnológica no meio acadêmico e em estudos de monitoramento tecnológico, no qual buscam-se as tendências do desenvolvimento de uma dada tecnologia e possíveis soluções que acabem, ou melhorem, o estado dessa problemática.

\section{Metodologia}

A metodologia adotada foi de uma pesquisa de caráter quali-quantitativa e exploratório-descritiva, para a caracterização da temática e descrição do universo a ser estudado. Como procedimento metodológico fez-se uso também do monitoramento tecnológico em bases de dados de patentes, e da análise de conteúdo como método de análise dos resultados, que foi feita dentro dos princípios do campo CTS que busca a construção de uma sociedade economicamente estável, ambientalmente saudável e socialmente justa. Com vistas ao referencial teórico apresentado pretendeu incentivar a interação entre os estudos das áreas de Propriedade Intelectual, os estudos CTS e a questão da sustentabilidade ambiental.

Para tanto, esta pesquisa foi realizada seguindo-se as seguintes etapas:

1) Levantamento bibliográfico para compor a revisão de literatura;

2) Levantamento de termos/palavras-chave representativas para a realização do monitoramento tecnológico, através da literatura encontrada sobre descarte de lixo tecnológico, esperando-se que com estas obtenha-se eficiente recuperação de informações relevantes no universo da base de dados de patentes selecionada; 
3) Seleção da base de dados de patentes a ser utilizada;

4) Realização de pré-testes para verificação da eficiência das palavraschaves levantadas;

5) Testar a eficiência e realizar a coleta dos dados, do contrário, efetuar novos estudos na literatura da área de descarte de lixo tecnológico a fim de encontrar termos relevantes para a busca;

6) Tratamento dos dados coletados quali-quantitativamente;

7) Análise dos resultados através da análise de conteúdo.

Para a delimitação do universo a ser estudado, realizou-se um levantamento das fontes de informação formais a serem utilizadas para o estudo do universo. Para a recuperação e coleta das fontes de informação supracitadas, utilizou-se as seguintes bases de dados: Google; Google Acadêmico; Scielo; Web of Science; Scopus; Compendex; JusBrasil; Diário Oficial; Derwent Innovations Index; Espacenet, e outras bases de dados de patentes.

Foi realizado, posteriormente, o levantamento das principais bases de dados de patentes e um pré-teste com os termos de busca, previamente retirados da literatura, a fim de comparar a facilidade dos mecanismos de busca de cada base de dados, sua interface e o quanto cada base recuperou por palavra-chave. Tais bases de dados selecionadas para o préteste de exploração foram: (1) Espacenet (do escritório europeu de patentes); (2) Google Patents (base de dados americana usada como alternativa à USPTO); (3) INPI (base de dados do Instituto Nacional da Propriedade Industrial, do Brasil); (4) IPDL (Industrial Property Digital Library, base de dados do escritório japonês de patentes); (5) PatentScope (base de dados de patentes da Organização Mundial da Propriedade Intelectual); (6) USPTO (base do escritório americano de patentes (United States Patent and Trademark Office)); (7) Derwent Innovations Index (base de dados de patentes internacionais).

Comparados os resultados recuperados com os pré-testes realizados nas bases de dados, concluiu-se que a base de dados de patentes que melhor representaria o universo a ser estudado seria a Espacenet, cuja representatividade está no fato desta ser online, gratuita, multidisciplinar (patentes de diversas áreas do conhecimento) e abranger as patentes depositadas na base de dados do escritório brasileiro de patentes, Instituto Nacional da Propriedade Industrial (INPI), e outros 85 países, contendo patentes publicadas a partir do ano de 1836 até o presente (ESPACENET, 2011).

É importante ressaltar que a opção de se pesquisar em bases de dados gratuitas baseou-se em questões de sustentabilidade e acessibilidade da informação com menor impacto econômico, assim como o fato da utilização dos documentos de patentes como fonte de informação para o monitoramento tecnológico, e não qualquer outra, se deve ao fato de as patentes terem se mostrado uma eficiente ferramenta e um instrumento eficaz no apoio à tomada de decisão.

Tendo em vista seu conteúdo informacional, um documento de patente permite identificar tecnologias relevantes, parceiros, nichos de mercados para atuação, inovações incrementais e movimentos da concorrência, tais 
como investimentos, gestão de processos, gestão de produtos, novas linhas de Pesquisa e Desenvolvimento (P\&D), fusões e aquisições, dentre outras, como aborda Canongia, Pereira e Antunes (2002).

O universo desta pesquisa foi compreendido, portanto, pelos termos utilizados como sinônimo sobre novas tecnologias em descarte de lixo tecnológico, os quais foram utilizados entre aspas, para recuperação da expressão exata, e somente nos campos título e resumo. Os termos em português foram utilizados sem a devida acentuação tendo em vista que a base Espacenet não os indexa, sendo que seu uso ocasionariam sucessivos erros de sintaxe. No total, foram selecionados 37 termos/palavras-chave e um universo de 31 documentos de patentes recuperados a serem analisados.

A seção seguinte apresenta os resultados da presente pesquisa juntamente da discussão e, em seguida, das conclusões do estudo.

\section{Resultados}

A partir do estudo do universo levantado, constatou-se maior incidência na recuperação de documentos nas buscas realizadas com os termos no idioma inglês, sendo que os termos "electronic waste" e "electronic scrap" foram os que mais recuperaram, com 13 documentos de patentes cada um. Em seguida ficou o termo "technological waste", que recuperou 2 documentos de patentes. Os termos "waste disposal technology" e "waste electrical and electronic equipment" recuperaram um documento de patente cada. As demais palavras-chave selecionadas, tanto as em inglês como as em português, obtiveram resultado nulo quanto à recuperação na base de dados de patentes Espacenet.

No período de tempo analisado (2003 a 2011) observou-se a ocorrência de registros de pedidos de patentes recuperados por termo, conforme apresentado na Tabela 1.

\begin{tabular}{lllllll}
\hline ANO & $\begin{array}{l}\text { "waste } \\
\text { disposal } \\
\text { technology" }\end{array}$ & $\begin{array}{l}\text { "waste } \\
\text { electrical } \\
\text { and } \\
\text { electronic } \\
\text { equipment" }\end{array}$ & $\begin{array}{l}\text { "technological } \\
\text { waste" }\end{array}$ & $\begin{array}{l}\text { "electronic } \\
\text { scrap" }\end{array}$ & $\begin{array}{l}\text { "electronic } \\
\text { waste" }\end{array}$ & TOTAL \\
\hline $\mathbf{2 0 0 3}$ & 1 & 0 & 1 & & & \\
$\mathbf{2 0 0 4}$ & 0 & 0 & 0 & 1 & 3 & 4 \\
$\mathbf{2 0 0 5}$ & 0 & 0 & 0 & 3 & 0 & 3 \\
$\mathbf{2 0 0 6}$ & 0 & 0 & 0 & 3 & 0 & 3 \\
$\mathbf{2 0 0 7}$ & 0 & 0 & 1 & 0 & 2 & 3 \\
$\mathbf{2 0 0 8}$ & 0 & 1 & 0 & 2 & 2 & 5 \\
$\mathbf{2 0 0 9}$ & 0 & 0 & 0 & 1 & 3 & 4 \\
$\mathbf{2 0 1 0}$ & 0 & 0 & 0 & 0 & 2 & 2 \\
\hline TOTAL & $\mathbf{1}$ & $\mathbf{1}$ & $\mathbf{2}$ & $\mathbf{1 3}$ & $\mathbf{1 3}$ & $\mathbf{3 0}$ \\
\hline \multicolumn{7}{c}{ Tabela 1: Número de registros de documentos de patentes sobre REEE } \\
recuperados por termos por ano de prioridade na base Espacenet. &
\end{tabular}

Analisando-se os pedidos de patentes acima mencionados, observouse, quanto à origem de seu depósito, que 11 deles foram depositados 
somente nacionalmente, visto que o processo não fez uso do Tratado de Cooperação de Patentes (PCT).

Em contraposição, outros 19 pedidos de patentes recuperados tiveram seu depósito nacionalmente e também fizeram uso do Tratado PCT ao entrar com o pedido da patente na WIPO (WO), ou no escritório americano de patentes (USPTO), ou no escritório de patentes da União Europeia (EPO), e/ou em outros países cujo mercado lhes foi de interesse. Tal fato, de pedido internacional, indica que os inventores e requerentes (depositantes) da patente têm interesse em proteger sua tecnologia em outros possíveis mercados além de seu país de origem, isto é, os países que também receberam o pedido de proteção da patente são considerados, pelos depositantes, possíveis mercados para a comercialização da tecnologia reivindicada.

A Figura 1 apresenta o número de registros de pedidos de patentes por data de depósito e data de publicação dos pedidos de patentes recuperados ao longo do período de tempo (2003 a 2011) analisado. A data de depósito é a data registrada no protocolo do pedido de patente para o depósito nacional, ou a data do registro do pedido internacional, sendo que este deve ocorrer dentro do prazo de prioridade (período de 12 meses contados da data do pedido no país de origem do depósito do pedido via PCT). Diferentemente da data de depósito, a data de publicação refere-se à data na qual o pedido de patente nacional teve seu período de sigilo findado (18 meses contados a partir da data de depósito). Tal data pode se referir também à notificação da entrada na fase nacional do pedido internacional depositado via PCT.

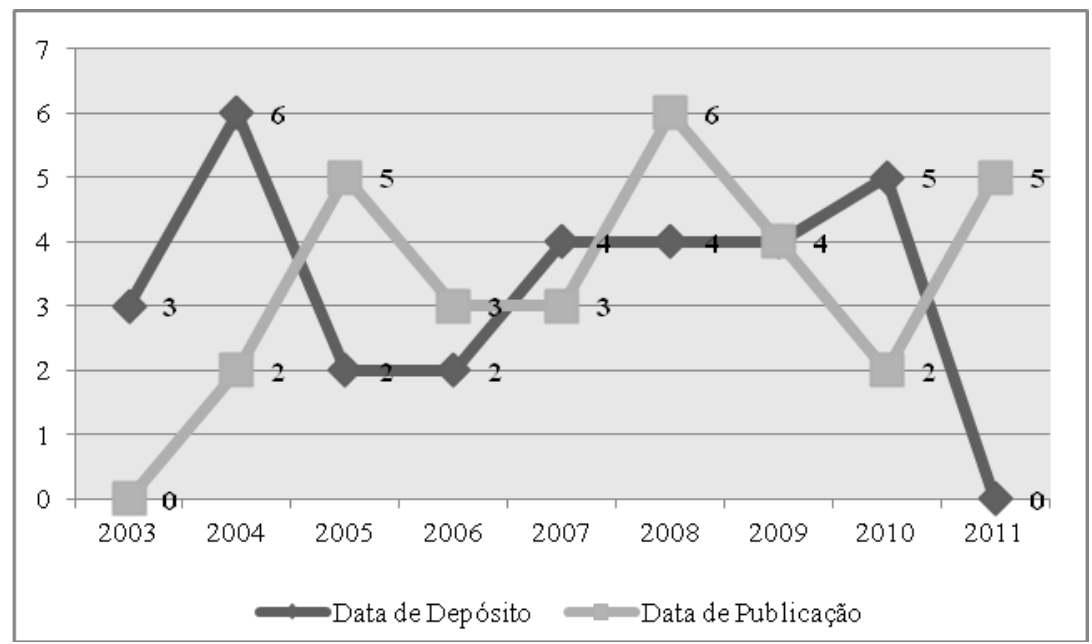

Figura 1: Número de registros de documentos de patentes recuperados sobre REEE por data de depósito e de publicação na base Espacenet.

Fonte: Elaboração própria.

Como observado, três pedidos foram depositados em 2003, seis em 2004, dois em 2005 e em 2006, quatro depositados em 2007, 2008 e 2009, cinco em 2010 e nenhum em 2011. Consequentemente, dois pedidos foram 
publicados em 2004, cinco em 2005, três em 2006 e em 2007, seis em 2008, quatro em 2009, dois em 2010 e cinco em 2011.

Tais discrepâncias no período de sigilo dos pedidos podem ser justificadas devido ao fato de que, segundo Macedo e Barbosa (2000, p. 45), "após o depósito do pedido de patente perante a autoridade governamental competente de cada país, o mesmo passa por diversas etapas assemelhadas", sendo que as diferenças das legislações nacionais são, preponderantemente, pela existência ou exclusão de alguma etapa na tramitação do pedido.

Os depositantes e a natureza jurídica destes também foram levantados. Os depositantes que mais se destacaram foram dois pesquisadores, classificados como pessoa física, sendo um da Alemanha (Koslow, Alexander) e o outro dos Estados Unidos da América (Akridge, James R.). Todos os demais apresentaram somente um registro de pedido de patente sobre REEE recuperado.

Dentre todos os 51 depositantes do universo analisado, a Figura 2, apresenta os registros de pedidos de patentes recuperados por nacionalidade. Observa-se que a Alemanha lidera possuindo 12 depositantes, seguida pelos Estados Unidos da América, com 9. A República Tcheca e a Finlândia possuem ambos 5 depositantes cada, assim como a Itália e a Polônia, com 4 depositantes cada um. A Hungria, o Reino Unido e a Suíça apresentaram três depositantes de pedidos de patentes cada, enquanto que a França, Israel e Turquia finalizam o ranking com apenas um pedido de patente cada um.

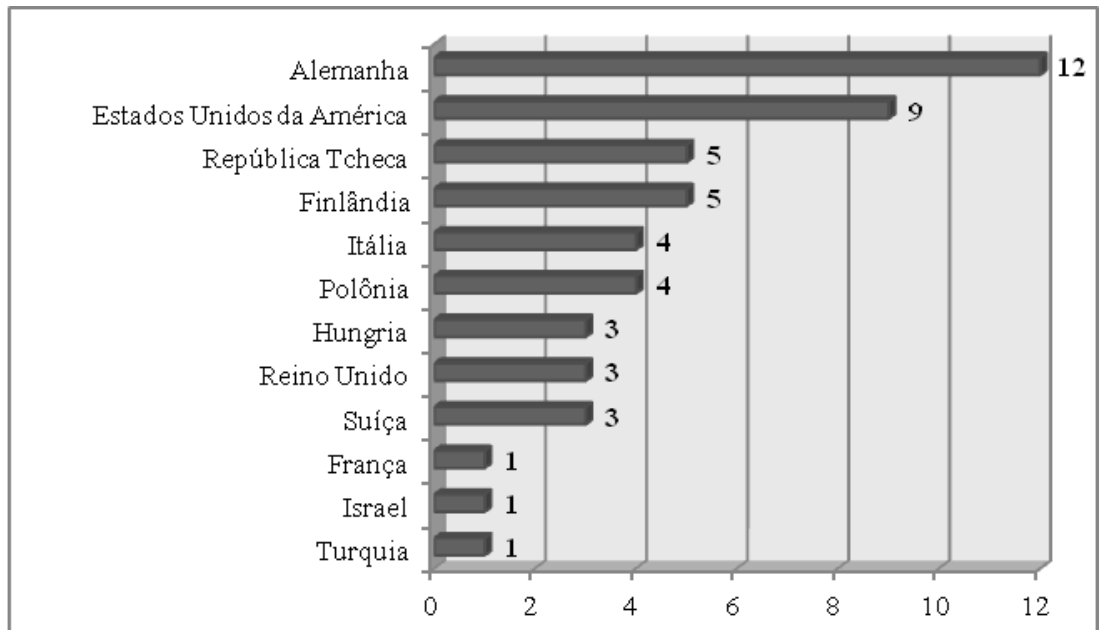

Figura 2: Número de registros de documentos de patentes recuperados sobre REEE por nacionalidade de seus depositantes.

Fonte: Elaboração própria.

Quanto às tipologias dos registros de pedidos de patentes recuperados, obteve-se 21 pedidos de patente de invenção reivindicando processos, e, nove reivindicando produtos. Quanto ao idioma dos registros dos pedidos de patentes recuperados, foram recuperados 21 documentos em inglês, oito em alemão e somente um em francês. 
Conforme os idiomas acima mencionados, a nacionalidade dos pedidos de patentes recuperados divide-se entre 13 países distintos. Assim como o idioma inglês é o que mais se destaca, os Estados Unidos da América também lidera o ranking dos países com registros mais recuperados, tendo 8 documentos registrados. Seguido de Alemanha, com seis registros; Suíça, com três; Itália, Finlândia e Canadá, com dois registros cada um; e, Turquia, República Tcheca, Reino Unido, Polônia, Japão, Israel e Hungria, com um registro cada um. Tais dados são apresentados na Figura 3.

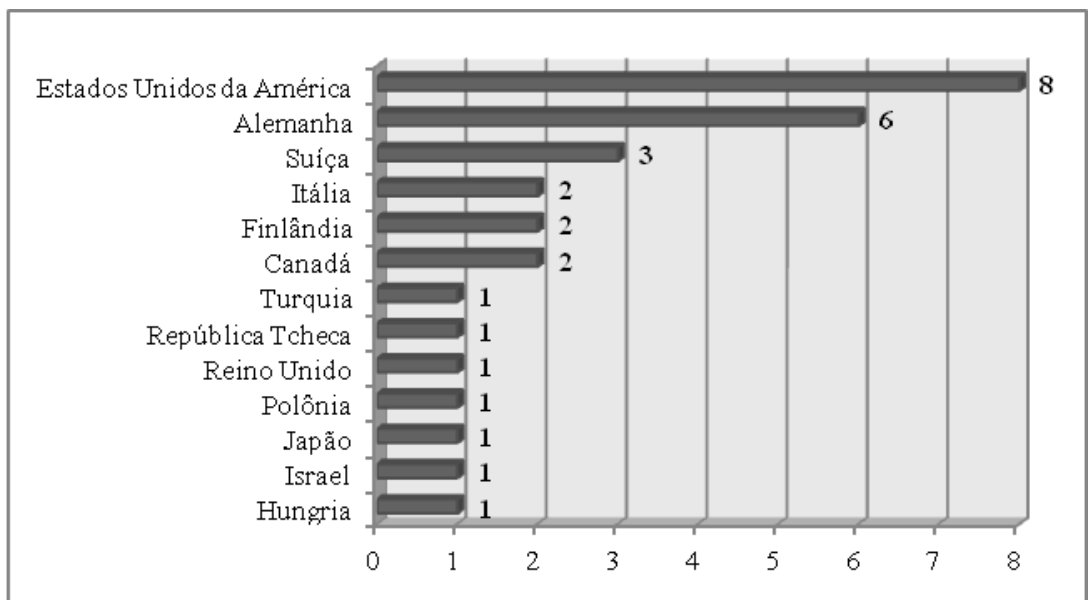

Figura 3: Número de registros por nacionalidade dos documentos de patentes recuperados sobre REEE na base Espacenet.

Fonte: Elaboração própria.

Por meio do estudo do conteúdo dos documentos de patentes e das aplicações nelas mencionadas, foi possível categorizar o universo estudado nos seguintes grupos de tecnologias:

1) Métodos/processos para separação de plásticos contidos na sucata eletrônica;

2) Métodos/processos para separação de metais nobres contidos na sucata eletrônica;

3) Recipientes (produtos) para o acondicionamento e transporte seguro (sem quebra dos equipamentos) de REEE;

4) Recipiente (produto) em forma de caixa-lembrete para a conscientização para a separação e o recolhimento de diversos tipos de materiais recicláveis, incluindo os de REEE;

5) Outras tecnologias não relacionadas à temática:

a. Processo de aquecimento solar de água através de calor solar e/ou de resíduos de sucata eletrônica e/ou outros resíduos tecnológicos;

b. Software para jogos de computador;

c. Sistema para gestão da remoção de resíduos industriais;

d. Incinerador de resíduos orgânicos.

No que tange à análise do conteúdo desses documentos, através do formulário de análise de conteúdo, levou-se em consideração o 
aparecimento de termos ou expressões que evidenciassem a preocupação do inventor (ou escritor do pedido) da patente com a temática da sustentabilidade ambiental. Observou-se uma preocupação positiva nesta questão em 16 dos 30 documentos de patentes analisados.

Foi citada a necessidade do acondicionamento dos resíduos finais em aterros sanitários apropriados, conforme exposto no trecho a seguir: "as cinzas tratadas e drenadas são armazenadas junto com as cinzas da grelha em um aterro sanitário apropriado/adequado" (CH 696425 (A5)). Assim como o fato de aterros sanitários serem cada vez mais inaceitáveis por causa da contaminação do solo e das águas subterrâneas devido à lixiviação de contaminantes. Outros documentos evidenciaram também uma preocupação com o fato de que os resíduos de produtos despejados no meio ambiente demoram muito tempo para desaparecer por si só na natureza, causando poluição ambiental e ameaçando a saúde humana e a saúde ambiental. A questão da sustentabilidade ambiental foi explicitada também através de uma preocupação com as matérias-primas resultantes e estas serem pura e facilmente reutilizáveis.

Apesar da clara preocupação e apontamento de termos e expressões relacionadas à sustentabilidade ambiental, dados numéricos relacionados à questão da sustentabilidade ambiental somente foram identificados em três, dos 30 , registros de patentes analisados. Tais dados foram identificados em registros da Alemanha, da Finlândia e dos Estados Unidos da América, respectivamente.

No que diz respeito à importância (social e/ou econômica) da tecnologia reivindicada para a sociedade, 10 documentos de patentes analisados apresentaram preocupação e destacaram sua importância ao longo dos documentos. Exemplo desta questão é mencionado num pedido de patente inglês, número de prioridade GB20080001820, que destaca a necessidade do depósito dos REEE ser feita de forma segura e ambientalmente amigável ("depositar os REEE de forma segura ambientalmente amigável").

Um pedido de patente chamou a atenção pela extensa preocupação social descrita ao longo do documento. O pedido de número de prioridade (US20100836806) pertencente aos Estados Unidos da América explanou que "os custos sociais nesses lugares menos afluentes é muitas vezes chocante, usando trabalho infantil, com pouca ou nenhuma preocupação para a segurança industrial, e os trabalhadores expostos à paisagem circundante de poluentes químicos".

Foi interessante constatar que tal pedido de patente, cujo processo permite a redução do lixo eletrônico através de atualizações do dispositivo eletrônico afim de não torná-lo inutilizável tão rapidamente quanto a indústria espera, cita o fato de que "ironicamente, muitas pessoas em lugares mais ricos só se dão conta de tudo isso [trabalho infantil e ambiente de trabalho inóspito] quando alguns desses poluentes químicos cruzar o seu caminho, em novos processos de fabricação, e voltam a eles por meio do alto teor de chumbo em brinquedos e substâncias cancerígenas no vestuário".

A preocupação com a sustentabilidade ambiental também foi requerida no questionário de análise de conteúdo através de outra questão, mas desta 
vez no tocante à própria tecnologia cuja patente está sendo requerida. Nesta, questionou-se se o documento traz informações sobre como proceder com o descarte de tal tecnologia após o término de seu ciclo de vida. Tal prerrogativa não foi evidenciada em 27 dos documentos de patentes analisados, estando presente, portanto, em somente três registros.

Com relação ainda à questão da sustentabilidade, questionou-se a presença, ou não, de termos ou expressões relacionados a possíveis riscos ambientais. Do universo analisado, somente nove pedidos de patentes apresentaram tais termos. Os pedidos de patentes que apresentaram termos ou expressões relacionados aos riscos ambientais, das tecnologias reivindicadas ou a ela relacionadas, relacionam-se com a questão do descarte ambientalmente inadequado dos rejeitos da sucata eletrônica e aos impactos por estes gerados em aterros sanitários impróprios, assim como ao meio ambiente de forma geral.

Sendo assim, observou-se, no universo analisado, grandes contrastes evidenciados tanto por reivindicações puramente técnicas como por documentos que levaram em consideração mais do que somente uma descrição sumária da tecnologia em questão. A próxima seção apresenta uma sinopse dos principais resultados e a importância destes para a sociedade à luz das conclusões do estudo.

\section{Considerações finais}

Esta pesquisa teve como intuito realizar análise de patentes de tecnologias relacionadas ao descarte de lixo tecnológico e das tendências verificadas por meio de documentos de patentes, por meio de monitoramento tecnológico de produtos e processos na base de dados de patentes gratuita online Espacenet, além de contribuir e incentivar uma interação entre a área de Propriedade Intelectual com os estudos do campo CTS e a questão da sustentabilidade ambiental.

Conforme apontado anteriormente, os resultados analisados indicaram forte preocupação com questões relacionadas à sustentabilidade ambiental, considerando desde possíveis termos ou expressões e dados numéricos relacionados à sustentabilidade, passando pela descrição da importância dessas tecnologias para a sociedade, suas aplicações e possíveis mercados, até informações de como se proceder com o descarte de tais tecnologias ao término de seu ciclo de vida, suas vantagens e desvantagens, riscos ambientais envolvidos e legislações citadas por esses documentos de patentes.

Constatou-se que o idioma inglês predominou nos documentos do universo analisado, sendo os Estados Unidos da América o país líder no ranking dos que patentearam tecnologias de descarte e reciclagem de REEE, seguido de perto por Alemanha e Suíça. Houve menção de outros países como Itália, Finlândia, Canadá, Turquia, República Tcheca, Reino Unido, Polônia, Japão, Israel e Hungria, o que denota que o estudo de técnicas e práticas que envolvam o reaproveitamento e a reciclagem de resíduos de sucata eletrônica está em difusão pelo mundo. 
Os resultados indicaram também o aparecimento de termos ou expressões que evidenciaram a preocupação do inventor (ou escritor do pedido) da patente com a temática da sustentabilidade ambiental em $51 \%$ do universo estudado. No que diz respeito à importância (social e/ou econômica) da tecnologia reivindicada para a sociedade, 10 documentos de patentes analisados apresentaram preocupação e destacaram sua importância ao longo dos documentos.

A preocupação com a sustentabilidade ambiental, porém, não foi evidenciada na análise no que dizia respeito à presença de informações sobre como proceder com o descarte de tal tecnologia após o término de seu ciclo de vida. Tal prerrogativa não foi evidenciada em 27 dos documentos de patentes analisados. Quanto aos termos e expressões relacionados aos possíveis riscos ambientais a que tais tecnologias estariam relacionadas, somente nove, dos 30 pedidos de patentes do universo, apresentaram tais termos.

Conforme aponta o campo CTS, a tecnologia, assim como a ciência, é feita para os pares e, consequentemente, a sociedade acaba por ser excluída do debate e das reflexões a respeito das implicações sociais da ciência e da tecnologia. Disponibilizar o acesso é obrigação da União e tornar as bases de acesso público inclusivas, e não restritivas, também.

Infere-se que, do ponto de vista abarcado pelo campo CTS, a informação tecnológica tem implicações diretas para a sustentabilidade ambiental, tanto no que diz respeito às suas fontes, seu conteúdo, quanto em seu uso. O comunismo do conhecimento científico, conforme apontado por Merton (1979) no aporte teórico da dissertação que deu origem a este artigo (GIGANTE, 2012), apesar de idealizado, se seguido à risca, possibilitaria maior interação e colaboração das diversas áreas do conhecimento, inclusive as relacionadas à questão da sustentabilidade sócio-econômica-ambiental.

Relacionado a isso, há, porém, que se considerar o fato de nossa sociedade ser capitalista e ter uma economia com bases fortemente alicerçadas no tripé da alta produtividade, curta meia vida dos produtos e alto consumismo. Por isso, por mais que cientistas e tecnólogos se esforcem para criar produtos ambientalmente corretos para minimizar ou corrigir os impactos gerados pelos demais produtos já criados pela humanidade, e globalmente difundidos, eles sozinhos não conseguirão reverter todo o impacto e desastres já gerados.

O campo CTS confirma e universidades, governo e sociedade como um todo têm que se unir para que novas práticas ambientalmente seguras sejam criadas e adotadas mundialmente a fim de que parte do impacto já gerado seja revertido, ou, numa visão mais realista, que novos impactos não sejam gerados ou ainda, apenas minimizados.

\section{Agradecimentos}

As autoras agradecem à Fundação de Amparo à Pesquisa do Estado de São Paulo (FAPESP) e à Coordenação de Aperfeiçoamento de Pessoal de Nível Superior (CAPES) pelo apoio financeiro. 


\section{Notas de fim}

1 Este artigo apresenta os resultados da pesquisa do Mestrado em Ciência, Tecnologia e Sociedade, desenvolvido na Universidade Federal de São Carlos, pela autora, tendo sido orientada pela [REMOVIDO P/ REVISÃO ANÔNIMA].

2 Uma versão aproximada deste trabalho foi apresentada no ESOCITE - IX Jornadas Latinoamericanas de Estudios Sociales de la Ciencia y la Tecnología, que ocorreu em Junho de 2012, em Ciudad de México-DF, México.

\section{Referências}

BAZZO, W., LINSINGEN, I.V.; PEREIRA, L.T.V. Introdução aos estudos CTS: (Ciência, Tecnologia e Sociedade). Madri: OEI, 2003. (Cadernos lbero-América).

CANONGIA, C., PEREIRA, M.N.F.; ANTUNES, A. Gestão da informação e monitoramento tecnológico: o mercado dos futuros genéricos. Perspectivas em Ciência da Informação, v. 7, n. 2, jul./dez. 2002, p. 155-166.

ESPACENET. Página inicial. Disponível em: <http://lp.espacenet.com/>. Acesso em: 22 mar.2011.

FERRAZ, M.C.C.; BASSO, H.C. Resíduos sólidos formados por lixo eletrônico: riscos ambientais e política de reaproveitamento. In: Fórum das Universidades Públicas Paulistas: Ciência e Tecnologia em Resíduos, 1., São Pedro. Instituto de Ciência e Tecnologia em Resíduos e Desenvolvimento Sustentável, 2003, p. 286-296.

GIGANTE, L.C. Análise de patentes de tecnologias relacionadas a resíduos de equipamentos elétricos e eletrônicos. 219 f. Dissertação (Mestrado em Ciência, Tecnologia e Sociedade)- Universidade Federal de São Carlos, São Carlos, 2012.

HARVEY, D. Do fordismo à acumulação flexível. In: A condição pós-moderna. São Paulo: Loyola, 1993. p. 135-162.

LÓPEZ CEREZO, J.A. Ciencia, tecnología y sociedad: el estado de la cuestión en Europa y Estados Unidos. Revista Iberoamericana de Educación, v. 18, 1998, p. 41-68.

Ciência, tecnologia e sociedade: o estado da arte na Europa e nos Estados Unidos. In: SANTOS, L.W. (Org.) et al. Ciência, tecnologia e sociedade: 0 desafio da interação. Londrina: IAPAR, 2002. p. 3-39.

MACEDO, M.F.G.; BARBOSA, A.L.F. Patentes, pesquisa \& desenvolvimento: um manual de propriedade intelectual. Rio de Janeiro: FioCruz, 2000. 
MERTON, R.K. Os imperativos institucionais da ciência. In: DEUS, J.D. (Org.). A crítica da ciência: sociologia e ideologia da ciência. Rio de Janeiro: Zahar, 1979. p. 37-52.

SENNETT, R. A corrosão do caráter: as consequências pessoais do trabalho no novo capitalismo. Rio de Janeiro: Record, 2010. 